Published in: ZAS Papers in Linguistics 2004/33, 13-38.

\title{
On correlation between the emergence of finite verbs and the development of utterances in Russian and German*
}

\author{
Natalia Gagarina \& Dagmar Bittner \\ ZAS Berlin \\ gagarina@zas.gwz-berlin.de \& dabitt@zas.gwz-berlin.de
}

\begin{abstract}
The study examines the hypotheses that the acquisition of the finite verb is an indispensable and linking constituent of the development of SVO utterances. Four apparently separate or at least separable processes are analysed over 6 months in one Russian and one German child: a) the emergence of verbs in the child's utterances, b) the occurrence of correctly inflected (finite) verb forms, c) the development of multi-component utterances containing a verb, and c) the emergence of (potential) subjects and objects. Russian and German exhibit rich verb morphology, and in both languages finiteness is strongly correlated with inflectional categories like person, number and tense. With both children we find a correlation in the temporal order of these four processes and - what is more relevant for our study - a dependency of a certain development on the utterance level on the emergence of finite verbs. Further, our investigation shows that language-specific development comes in to play already when children start to acquire verb inflection and becomes more contrastive when we observe the onset of the production of the SVO utterances.
\end{abstract}

\section{Introduction}

\subsection{State-of-the-art of the research}

A high interest in the acquisition of verbal morphology and language specific syntactic rules had been observed in the last decades. Though we did not find comparative studies focused on the particular relationship we are interested in, i.e., the interrelation between the emergence of SVO (or full) sentences ${ }^{1}$ and the development of verb inflection, several recent findings deal with related problems. Those studies focus on the acquisition of verb inflection and its impact on verb-placement in German (Verrips \& Weissenborn 1992, Clahsen \& Penke 1992, Gawlitzek-Maiwald, Fritzenschaft, \& Tracy 1992), the relationship between third person singular subject pronoun case and agreement with hypothesis that these two grammatical subsystems develop together (Rispoli 1999), and categories of verbs and early sentences (Bloom 1994) in English. Bloom (1994), for example, argues that children learn grammar 'once verbs are productive in their speech'. His main interest, however, lies in the sphere of semantic-syntactic relationship between sentence constituents, and in the order of the development of verb relations/arguments. In 1990, Radford suggested that functional categories enable subject agreement, case and tense to co-develop, because they are reflections of a single syntactic component. Later Loeb \& Leonard (1991) attempted to verify the co-development hypothesis by investigating the correlation between subject-verb agreement and the rate of pronoun case error.

We are very thankful to Jason Mattausch for his comments on this paper.

1 For this study we analysed only utterances with direct objects. 
Another contribution of Clahsen \& Penke (1992) showed that the acquisition of verb inflection leads to the accessibility of the functional projection IP, so that an inflected verb moves to the second position in the sentence. Works of Weissenborn (1990a, 1990b, 1994), concerning the correlation between the acquisition of verb inflection and the position of verbs and point out that it is necessary to differentiate between the acquisition of verb inflection and the features constituting agreement.

In German, the acquisition of the differences between finite and non-finite forms has an impact on the acquisition of the obligatory position of a verb and is not a decisive factor for the acquisition of subject-verb agreement (as it was proposed by other researchers, e.g. Clahsen 1991). Basically, it was found that finiteness is the prime factor that influences the movement of the verb to its obligatory position in sentences. These studies did not claim that only the full acquisition of the verbal inflectional paradigm gives rise to further development. When the child has overcome the period of rote learning of inflected forms and started to use finite verbs productively (i.e. not restricted to a closed set of verbs ${ }^{2}$ ) each finite form is potentially associated with the structural properties of this class of verbs (cf. Bittner et al. 2003). This has become obvious with respect to the V2-position of finite verbs in German where finite verbs take the second position irrespective of whether the agreement or tense paradigm of the verb is completely acquired or not.

As for Russian, there are a number of works concerning either the acquisition of verb morphology (see, for example, Kiebzak-Mandera et al. 1997, Kiebzak-Mandera 1999, Poupynin 1996, 1998, etc.) or the development of sentence structure (Savosteenko 1995, Ceytlin 2000), but nothing has been done so far in the investigation of the correlation (if any) between these two processes.

Thus, studies undertaken here dealt with the investigation of (verbal) inflection and its relationship to and/or influence on the development of a certain morphological category or of a certain syntactical component. The present study focuses on the linkage between the acquisition of finite verb forms and the emergence of sentences with $\mathrm{S}$ and $\mathrm{O}$, called here 'full sentences'. As previous investigations have shown, finite verbs behave (are treated) differently in comparison with infinite verbs in various respects in child language. The aim of this paper is to look beyond the verb itself and discuss the effects of finiteness on other elements of the utterance and the structure of the utterance.

\subsection{Peculiarities of Russian and German}

As the source of investigation, two languages with interesting typological differences in syntax and morphology - Russian and German - have been chosen. Russian exhibits a considerably richer morphology on verbs and nouns than German. In the verb system, person and number are fully differentiated in present tense. There is no homophony in agreement categories and prodrop omission of subjects is widespread. In the past tense, verbs are inflected according to number and gender. Russian, unlike German, assigns perfective and imperfective aspect on the verb. Furthermore, no copula exists in the Russian present tense. Thus, sentences without verbs are possible, like Den' 'It is a/the day' or On lingvist 'He is a linguist'. German verb inflection is characterised by homophonies in person/number-marking in all tenses and shows up in a much greater number of analytic constructions with verbs than in Russian.

\footnotetext{
2 Cf. a detailed study on the development of verb inflection in Russian in Gagarina (2000/2003) and in German in Bittner (2000/2003a; investigating the same German child as in the present study).
} 
In noun inflection, Russian assigns fusionally gender, number and case. The system of noun inflection exhibits a great deal of homophony. Along with the 3 genders and 2 numbers, 6 cases exist. There is no article in Russian.

Noun inflection in German is even more reduced. Like in Russian, gender, number and case are the nominal categories. However, they are mainly assigned on accompanying elements of the noun as there are determiners, adjectives, etc. showing a great amount of homophony. In syntax, especially word-order, Russian is much more free than German. Whereas German strictly shows V-2 position in main clauses and V-final in subordinated clauses as well as basic word order rules for the different sentence types, Russian (although basically showing $\mathrm{SVO}$ ) is not fixed in placing the verb or other elements. Thus, the predominant rule that components containing old information precede the components containing new information is valid for Russian. Russian and German, on the one hand, exhibit some typological similarities and, on the other hand, are different enough to provide a useful basis for the investigation aimed at here.

\section{Method}

\subsubsection{Subjects and data collection}

The analyses are based on longitudinal data of one Russian boy in the age range of $1 ; 5-2 ; 5$ and one German girl in the age range of $1 ; 8-2 ; 2$.

The Russian boy, Vanja, is the first child in a middle-class family living in St. Petersburg. At the time of recordings he mainly stayed at home with his grandmother. The child was basically recorded and/or video-taped about four hours a month between 1;5 and 2;7. However, during the period when the crucial lexical and inflectional development started $(2 ; 1$ to 2;3) the length of recordings reached six hours a month. The recording sessions were divided into two or three portions so that these portions of data per month have (a) relatively equal quantity, (b) minimal intervals between the sessions.

The German girl, Anna, is the only child of a middle class family living in Berlin. Anna has been recorded and video-taped two times a month in the age range from $1 ; 8.10$ to $2 ; 10$. Recordings mainly took place at Anna's home and lasted from 45 to 90 minutes. The interviewer - Dagmar Bittner - was very familiar with the family and the child already before the onset of the recordings. The mother and/or the father often took part in the recording sessions.

\subsubsection{Transcription and coding}

The tapes were transcribed into computer files in the CHAT format (MacWhinney 1995) almost immediately after audio- and video-recordings. All the transcripts were then checked by another transcriber. ${ }^{3}$ The morphological coding of the Russian data was performed on the basis of the automatic morphological analyser MORCOMM which is compatible with CLAN format programs and which was modified specially for coding of child language data (see Voeikova 2000, Gagarina et al. 2003).

All utterances containing only non-understandable material, interjections, 'yes/no' comments and their variations, and/or citations of songs, nursery rimes and so on were excluded from

For their help in transcribing and coding the data we are thankful to Elena K. Limbah and Marina I. Akkuzina (Russian data), Franziska Bewer and Jörg von Thun (German data). 
the analysis. Immediate and complete imitations of adult utterances and frozen forms ${ }^{4}$ have been excluded from counting as well. Due to the peculiarities of the recordings of Russian data some non-immediate repetitions were excluded from the calculations, namely, when adults did not understand the utterances of the child and asked him to repeat what he already said. Another type of excluded utterances contains non-immediate self-repetitions of the child, when he insisted on his wishes and demands (having not got the requested things). The Russian verbal particle $n a$ 'take' has also not been calculated.

\section{Results}

In order to test the hypothesis we conducted the following four analyses: a) the emergence of verbs in the child's utterances, b) the development of correctly used finite verb forms, c) the (quantative) development of syntactic components and their inflections in verb utterances, and d) the emergence of (potential) subjects and objects. The findings are summarised in the next section.

\subsubsection{Analyses I: Occurrence and quantitative development of utterances with verbs}

\subsubsection{Vanja}

For each child we calculated the number of verbal utterances (VU) per recording in relation to the total amount of analysed utterances.

The Russian boy Vanja starts verb production at 1;8 with the lemma dat' 'give-inf', the only verb used during the following five months. This lemma (in the form of 1.sg.fut dam) can hardly be viewed as a 'regular' verb, but rather as a predecessor of a verb with highly generalised meaning assigned to various desirable events. Use of dam-dat' and imperative daj decreases by the age of 2;1a when the onset of verb production is observed. At 2;1a Vanja produces four verb lemmas: idjom 'let's go (by foot)', naden' 'put on-imp', spat' 'sleep-inf', upala 'fell down-past.fem'.

Fig. 1a shows the emergence and development of VU in Vanja's corpus from 1;8 to 2;6 with two curves - one excluding the occurrences of dam from the total amount of VU (bold line) and one containing only utterances with dam (dotted line). ${ }^{6} \mathrm{VU}$ with dam remain for a long period and disappear only by the age of 2;5a. Even at 2;4b when Vanja uses finite forms productively, the erroneous use of dam is registered. After grandmother's request to 'speak normally' Vanja correctly uses imperative $d a j$.

\footnotetext{
$4 \quad$ We determine frozen forms as inflected verb forms, which (frequently) occur with fixed meaning in fixed (or similar) contexts, like (das) geht/(das) geht nicht '(it) works/(it) doesn't work' in German or dam 'givepf.1.sg' in Russian.

5 The form idjom is calculated as frozen.

6 VU without dam is the basic measure for the calculations in the present study.
} 


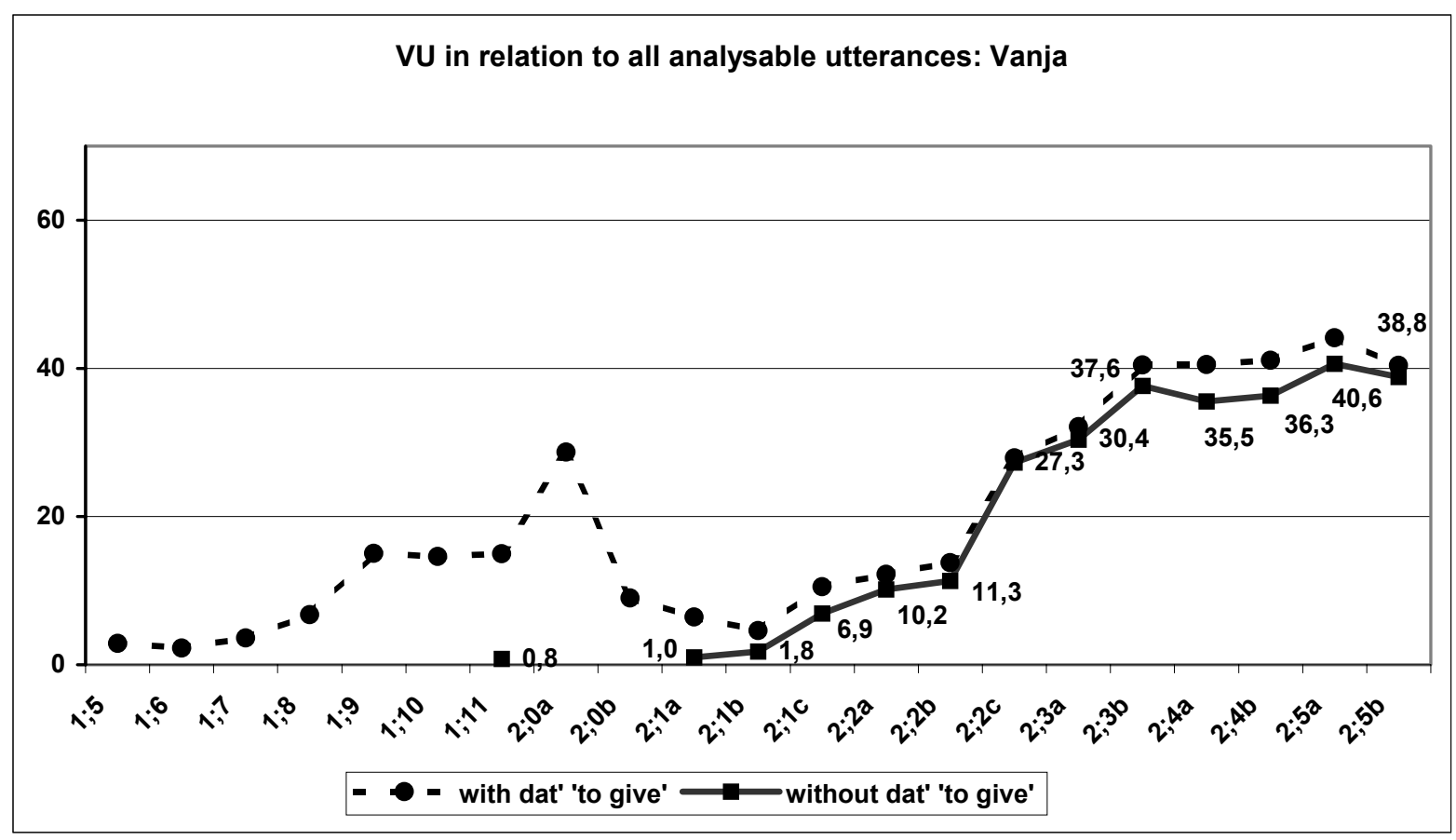

Fig. 1a

Starting with $2 ; 1 \mathrm{a}$, a regular increase in the VU production is observed. The steepest increase in VU is attested between $2 ; 2 \mathrm{~b}$ and $2 ; 2 \mathrm{c}$. In the short period of ten days the amount of VU in Vanja's data doubles from $11,3 \%$ to $27,3 \%$. We call it the 'spurt of VU'. Within the next month, VU reach $37,6 \%$. After the age of $2 ; 3 \mathrm{~b}$ and until the end of the investigated period, no spurts are observed, and the amount of VU only slightly increases to maximally $40,6 \%{ }^{7}$

With Vanja, we document an increase in newly attested lemmas shortly after to the spurt of VU and within the main increase. Tab. 1a shows that up to $2 ; 2 b-$ i.e. before the spurt of VU in sum 35 different verb lemmas are attested in the recordings. This number rises to 108 by the age of 2;3b: 65 new verb lemmas occur within one month.

\begin{tabular}{lcccccccccccc}
\hline Age & $2 ; 1 \mathrm{a}$ & $2 ; 1 \mathrm{~b}$ & $2 ; 1 \mathrm{c}$ & $2 ; 2 \mathrm{a}$ & $2 ; 2 \mathrm{~b}$ & $2 ; 2 \mathrm{c}$ & $2 ; 3 \mathrm{a}$ & $2 ; 3 \mathrm{~b}$ & $2 ; 4 \mathrm{a}$ & $2 ; 4 \mathrm{~b}$ & $2 ; 5 \mathrm{a}$ & $2 ; 5 \mathrm{~b}$ \\
\hline Tokens & 5 & 16 & 38 & 35 & 48 & 111 & 205 & 290 & 237 & 215 & 261 & 249 \\
\hline Lemmas & 4 & 7 & 12 & 18 & 23 & 28 & $\mathbf{5 2}$ & 78 & 77 & 67 & 156 & 95 \\
\hline New & 3 & 3 & 8 & 9 & 12 & 8 & $\mathbf{2 6}$ & 39 & 35 & 24 & 33 & 27
\end{tabular}

lemmas

Table $1 a^{8}$

It has been checked that the high amount of new verb lemmas does not result from longer time duration of the recordings (e.g. 2;2a $125 \mathrm{~min}$. and 2;3b $140 \mathrm{~min}$ ).

\subsubsection{Anna}

The German child has already started verb acquisition before the onset of the recordings, i.e., before $1 ; 8.10$. In the first recording, already $18 \%$ of Anna's utterances contain a verb, and 25

\footnotetext{
7 It is worth noting that child's speech behaviour is partially dominated by the questions of adults, who tried to stimulate Vanja's speech production.

8 In this table, VU with dat' are included into the calculation.
} 
verb lemmas are attested in the 65 minutes of recording. Nevertheless, as Fig. $1 \mathrm{~b}$ shows, we can observe a remarkable increase in verb usage in the following months. The sharpest increase happens from 1;10.0 to 1;11.6. In this short period the amount of VU has grown from 302 to more than $50 \%$. A secondary increase - slight spurt - of VU can be observed between $2 ; 0.5$ and $2 ; 1.27$ when the amount of VU goes up from $50 \%$ to nearly $70 \%$.

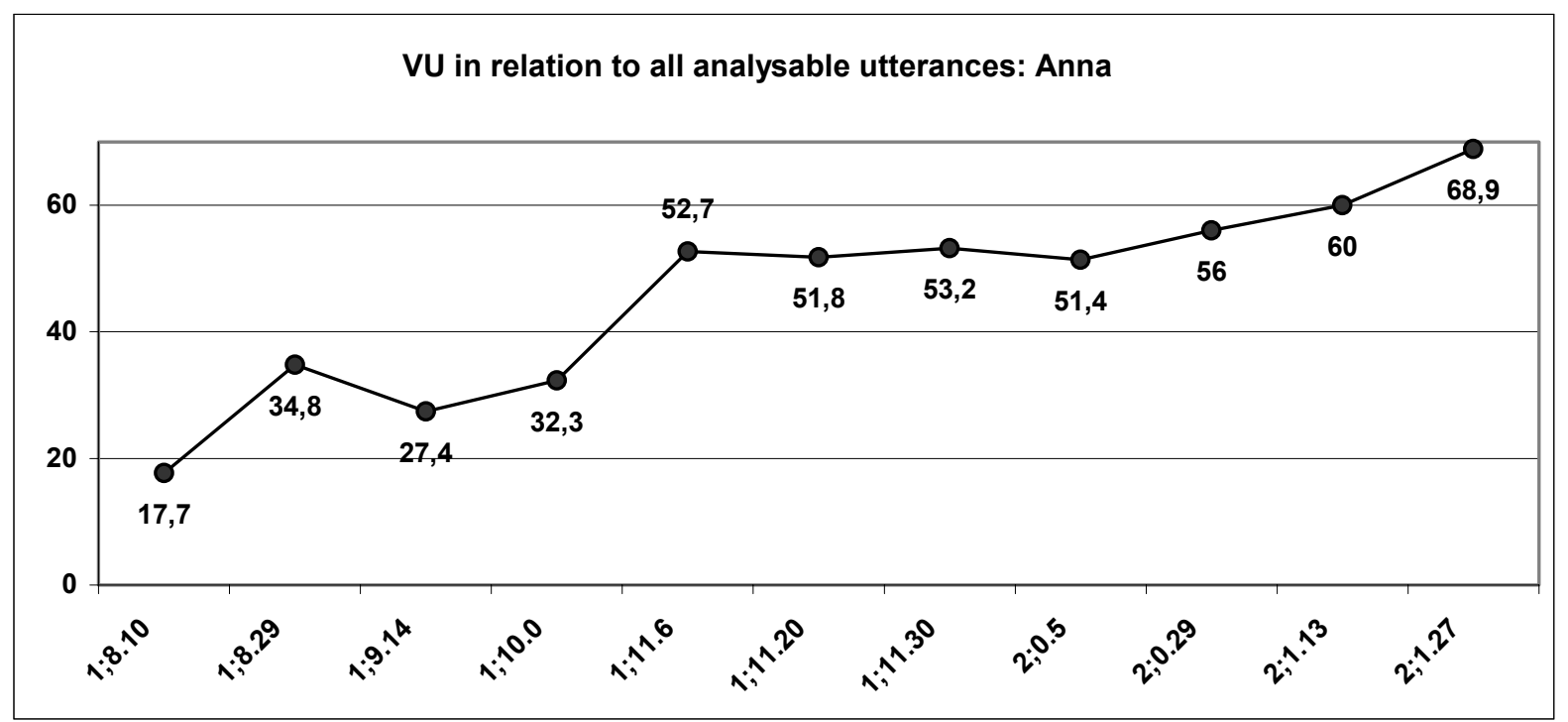

Fig. 1b

Also with Anna, the VU spurts show a correlation in time to increases of newly attested lemmas. In 1;11.6 and in 2;0.29 we find the highest amount of new lemmas per recording, cf. Table 1b:

Anna: lemmas/tokens

\begin{tabular}{cccccccccccc}
\hline Age & $1 ; 8.10$ & $1 ; 8.29$ & $1 ; 9.14$ & $1 ; 10.0$ & $1 ; 11.6$ & $1 ; 11.20$ & $1 ; 11.30$ & $2 ; 0.5$ & $2 ; 0.29$ & $2 ; 1.13$ & $2 ; 1.27$ \\
\hline Tokens & 45 & 47 & 53 & 66 & 145 & 114 & 93 & 112 & 277 & 203 & 305 \\
\hline Lemmas & 25 & 22 & 32 & 28 & $\mathbf{6 6}$ & 52 & 45 & 40 & $\mathbf{1 0 8}$ & 67 & 87 \\
\hline New lemmas & $(25)$ & 15 & 21 & 11 & $\mathbf{3 5}$ & 19 & 22 & 15 & $\mathbf{4 3}$ & 26 & 26 \\
\hline
\end{tabular}

Table $1 \mathrm{~b}$

It has been checked that the high amount of newly attested lemmas in $1 ; 11.6$ and $2 ; 0.29$ is clearly not a consequence of the length of recording.

\subsubsection{Inference: Vanja and Anna}

Comparing both children, we find an earlier onset and earlier increase (with respect to the onset of the verbal development) in verb usage with the German girl than with the Russian boy. The proportion of VU is higher in Anna's corpus than in Vanja's. Nevertheless, both children show comparable development in the use of VU. Within two months the percentage of VU increases $25 \%$ in both children. Further, we find clear spurts of newly attested verb lemmas with both children occurring in correlation with the spurts of VU. While Anna's spurt of VU co-occurs with the spurt in lemmas, Vanja's lemmas spurt lags slightly behind the VU spurt. The Russian boy starts the VU spurt by using already familiar verbs more frequently; later on the steep, continuing increase in VU overlaps with lemmas spurt. 


\subsubsection{Analyses II: Emergence of verb inflection}

Both children start their production of verbs with infinitives and rote-learned inflected forms (cf. Bittner 2000/2003a on German, Gagarina 2000/2003 on Russian). ${ }^{9}$ For the purpose of the present study we will merely focus on the development of (correctly used) finite forms and will comment on the other types of verb forms only according to their relevance for erroneous vs. correct use in target-like finite contexts.

\subsubsection{Vanja}

The first verbs of Vanja's lexicon are represented by infinitives, imperatives, and finite forms. Vanja employs infinitives as well as imperatives to express his wishes and demands. ${ }^{10}$ Both types of forms are 'legal' and maybe used in colloquial Russian. Infinitives are also frequently used in modal/future (irrealis) contexts with omitted finite modal verb or another finite component (these sentences are often marked by the imperative intonation), like (2;2c) rulit' sam 'drive-inf myself' in the meaning 'I want to/will drive by myself'. Rarely infinitives are used in present and past finite contexts: spat' 'sleep-inf' instead of spit 'sleep3.sg'. These contexts occur mainly as a child's answers to an adult's questions.

Finite verbs are employed from the onset of verb production, however, within the first 'onsetmonth' only a few instances of rote-learned forms are documented, upala 'fall-downpf.past.fem' at 2;1a, and masc. at 2;2c and two times spit 'sleep-ipf.3.sg'. After 2;1c their number consequently increases from $5,7 \%$ to $63 \%$ (with the two drops due to the peculiarities of the recordings at $2 ; 2 \mathrm{~b}$ and $2 ; 4 \mathrm{a}$ ). During the whole period of investigation the number of the non-target like used finite forms remains low $^{11}$ (and the types of these errors are rather stable). The errors mainly concern the use of gender/number in past forms, like upali 'fell-

9 For the purposes of this study it is not necessary to discuss the acquisitional steps towards productive morphology in detail (see, for example, Brown 1973, Mueller-Garthercole, Sebastian, \& Soto 1999, Bittner et al. 2003, etc.)

10 The use of infinitives in finite contexts is beyond of this paper (more on this issue see Avrutin 1999, BarShalom \& Snyder 1999, Gagarina 2002, etc.).

11 The low number of incorrectly used inflected forms should presuppose that the rate of correctly used finite forms in Vanja's speech should stay almost at the level of $100 \%$ percent. This is, however, not the case, because two types of potentially finite forms have not been included in the curve). The first type contains forms, which we call 'partially-unclear'. It means that the inflectional suffix of a verb form cannot be identified (due to the child's phonetic distortion and the specificity of the Russian pronunciation; for example, the strong reduction of the post-stressed vowels; change of unstressed $o$ into $a$, etc.) but the stem of a verb (lemma) is clearly distinct. Thus, sentences containing forms like (2;1c) poshjol=pisjo 'start-to-go-pf.past.sg.masc', (2;3b) postroil=pasto 'build-pf.past.sg.masc', (2;6a) ostavit=otjavi 'leave-pf.fut.3.sg' are included into the calculations of the analysable VU, but remain outside the curve 'correct finite forms'. With some lemmas like (2;2a) poexal=paexa we are able to clearly identify the open stem poexa-, which can be distinguished from the close stem poed-, but not the gender/number. Such cases are also calculated as unclear. Another type of forms, excluded from the curve, are imperatives, although they are (traditionally) treated as finite forms (see RG-80, Comrie \& Corbett 1993, Wade 1992, etc., but Jakobson (1984:7) wrote: 'imperative must ... be kept apart from the other verbal categories, since it is characterised by the same function as the vocative. The imperative ought not to be treated syntactically as a predicative form'). The singular form of an imperative in Russian bears no inflectional endings and is equal to a bare closed stem (which differs in some cases significantly from the open stem), and it can be, thus, more easily 'recognised' in the input, and produced by the child. It is known that children acquiring Russian use a high amount of imperatives from the onset of verb production. In Vanja, no significant changes in the use of this form were observed, except for the onset of verb production (before the inflectional spurt) when their number reaches $46 \%$, and for the period $2 ; 2 c-2 ; 3$ a when their number falls (and stays) at the level under $8 \%$. We would suggest, however, that the use of imperatives is determined more pragmatically than developmentally and depends (or may depend) on the types of recorded situations: compare $26 \%$ at $2 ; 4 \mathrm{a}$ vs. $6 \%$ at $2 ; 2 \mathrm{c}$. So, we come up with the low amount of correctly used intelligible inflected forms during the first months of verb production. 
down.pl' instead of upala 'fell-down.fem (2;2a), the use of number in present: gorit 'is burning' instead of gorjat 'are burning' $(2 ; 2 c)$, and the use of masculine instead of feminine/neuter with reflexive verbs: slomals'a 'break-masc.sg' instead of slomalas' 'breakfem.sg' (2;5a). Among the first correctly used finite forms (clearly distinctive) present/future forms of the imperfective/perfective and past forms of both aspects are documented.

The development of the correct use of verb inflection undergoes two considerable changes during the whole period of the investigation. The first more or less significant increase takes place between $2 ; 1 \mathrm{c}$ and 2;2a. The absolute number of correctly used forms (tokens) reaches 12 instances in comparison with 2 . All these forms, however, are rote-learned and are not yet very diverse. At 2;2a three imperfective lexemes are marked for the 3.sg. drive, stand, make noise and two perfective lexemes are marked for the past fall down, go away. Such increase cannot be even called a spurt, but more a 'probe' of the use of inflected forms.

The further drop ${ }^{12}$ in the correct use of verb inflection is followed by the considerable subsequent augmentation of the correctly used finite verb forms. This increase from $2 ; 2 \mathrm{~b}$ to $2 ; 2 \mathrm{c}$ may be indicated as an inflectional spurt. The number of correctly used inflected forms during this short interval increases from $16 \%$ to $56 \%$. This spurt still contains mainly forms of 3 rd present and of the past (Vanja has no other types of finite verb forms in this time), but some significant developmental changes distinguish this increase from the previous one. The number of verb lexemes (and inflectional classes involved) becomes more diverse. The opposition of 3.sg vs. 3.pl. occurs. Imperfective verbs obtain past tense inflection (which is very important for the development of the verbal grammatical categories, see below about the destruction of tense-aspect cluster), and all these inflected forms predominantly occur in sentences with several components. This spurt mainly consists of rote-learned forms, but we suppose that some forms may be already used productively, like the past tense form in the SVO structure djadja narisoval zajca 'man painted hare-acc.sg' or finite forms agreed with overt subjects fary gorjat 'headlight burns-ipf.3.pl', spit djadja 'sleep-ipf.3.sg a/the man', etc.

After 2;3a the number of correctly used finite forms slightly diminishes, although still remains at a high level. The diversity of forms and lemmas increases; Vanja starts to use forms of all three persons in sg and $\mathrm{pl}$ and learns to agree them with subjects in full SVO sentences. After the inflectional spurt reaches its peak (at 2;4a) the process of the development of the productive finite forms activates.

Analytical constructions, containing a finite verb and a non-finite component, occur only at 2;4a. These first instances include the verbal particle davaj 'let us', 2.pl of the verb pojdjom 'let's go', and an impersonal modal element nado 'it is necessary', mozhno 'it is allowed'. The auxiliary byt' 'to be' and finite modal verbs like hoču 'want-1.sg' occur even later, at the end of the $2 ; 4 \mathrm{~b}$ session.

12 At $2 ; 2 b$ the number of verbs with non-distinctive inflectional endings sharply increases. On the other hand, during this recording Vanja is occupied with drawing and often uses the imperative form of 'draw'. 


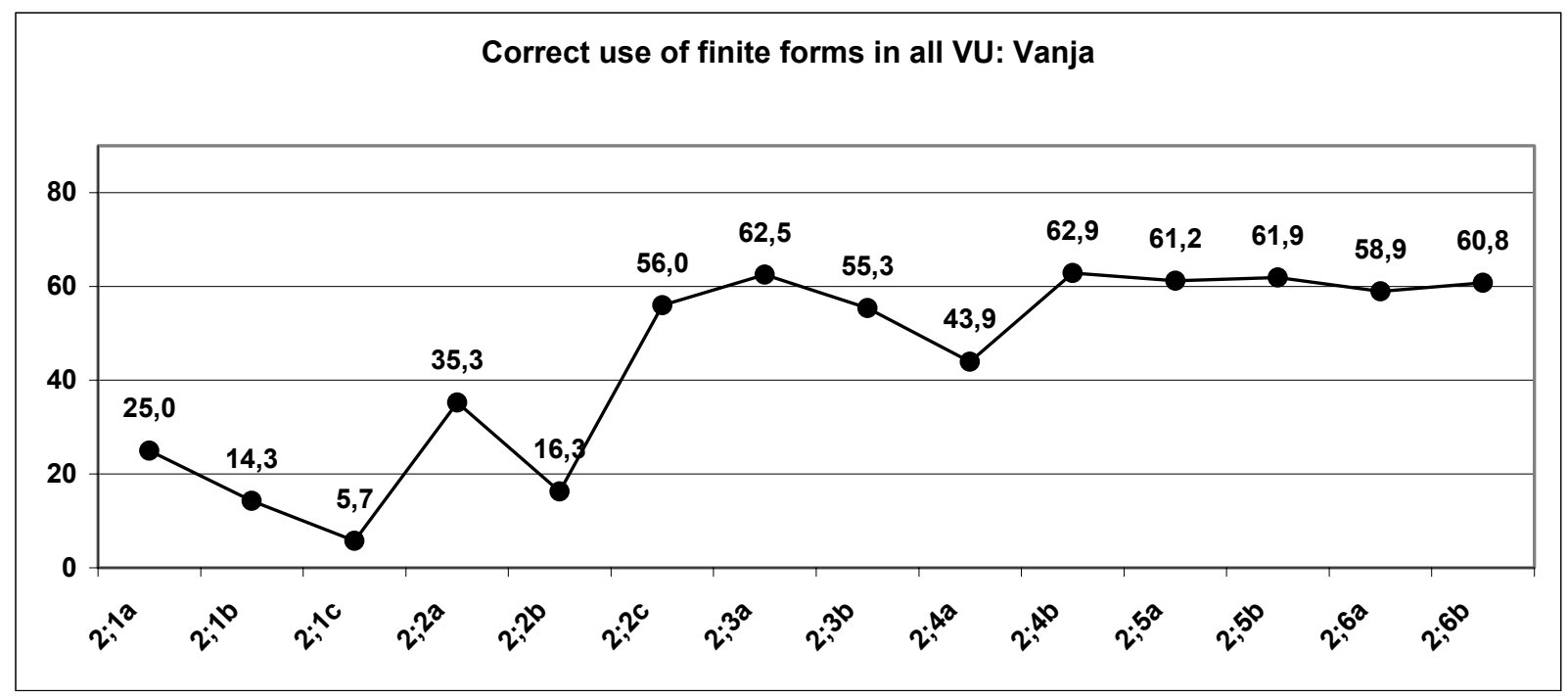

Fig. 2a

A comparison of Fig. 1a and Fig. 2a shows that in the data of Vanja the inflectional spurt coincides with the spurt in the production of VU. The absence of syncretism in the verb paradigm in Russian and the low significance of analytic constructions (except for future imperfective) for the acquisition of paradigm, as well as transparent form-function mapping facilitates the acquisition of verb inflection (i.e., results in the relatively stable successive development) and provides the basis for the simultaneous spurt in the development of VU and verb inflection.

The order of the emergence of inflected forms is:

2;1: ipf-pres.3.sg vs. pf-past (gender and number is not yet specified),

2;2: pf-past.sg vs. pf-past.pl, ipf-pres.3.sg vs. ipf-pres.3.pl, (sporadically: ipf-past vs. ipf pres, pf-past.sg.fem vs. pf-past.sg.masc),

2;3a: ipf-pres vs. ipf-past, first occurrence of the analytical future. More contrasts occur in $2 ; 3 \mathrm{~b}$ : present and future $1 . \mathrm{sg} / \mathrm{pl}$, future $3 . \mathrm{sg}$. Forms of $2 . \mathrm{sg} / \mathrm{pl}$ occur only at $2 ; 5 \mathrm{a}$.

\subsubsection{Anna}

Among the 45 verb tokens attested in the first recording $13(30 \%)$ are clearly used with target inflection. The remaining 32 forms are infinitives or stem forms (27) plus inflected forms for which the person/number context remains unclear (5). As Fig. $2 b$ shows, this initial situation holds on up to $1 ; 10.0$. At 1;11.6 - when we registered the first steep increase in the use of VU (Fig. 1b) - the amount of correctly inflected forms slightly decreases up to $20 \%$. After that, it increases within three weeks up to nearly $45 \%$. The steepest spurt in target inflection (i.e., inflectional spurt) is documented between $1 ; 11.20$ and $1 ; 11.30$. Note that this inflectional spurt takes place immediately after the increase of VU up to more than $50 \%$ (Fig. 1b) and after a spurt in the verb lexicon (Table 1b). Again, we find a second inflectional spurt after 2;0.29 following the second spurt in the emergence of VU (Fig. 1b) and in verb lexicon (Table 1b). 


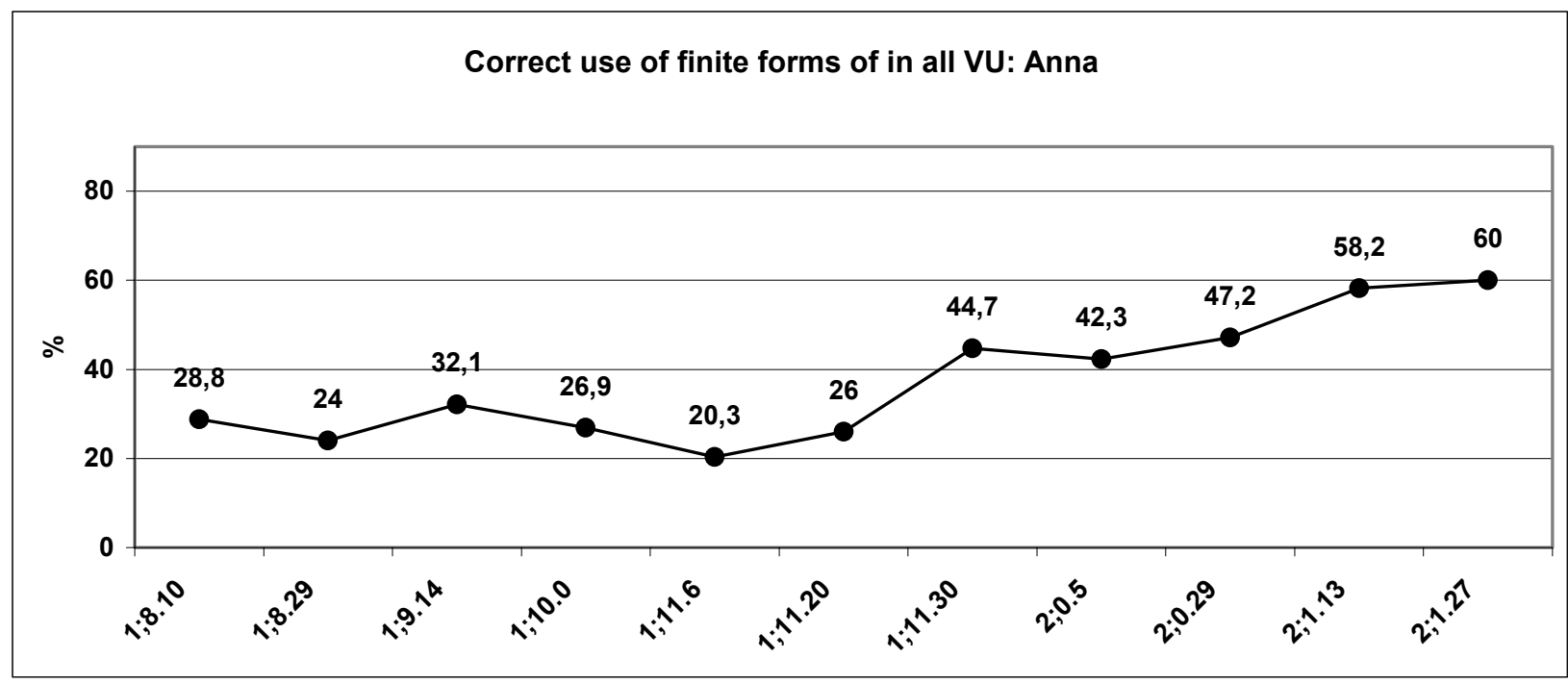

Fig. 2b

The decrease of correctly inflected verbs in $1 ; 11.6$ coincides with the strongest increase in newly attested verb lemmas before the age of 2;0 (cf. Table 1b: 66 verb lemmas used 35 new ones). It seems Anna is acquiring more verb lemmas and verb forms at once in this period than she can store by rote-learning. Obviously, the way out is to establish a default form of verbs, the -en form. It's proportion increases from $49 \%$ in $1 ; 10.0$ to $59 \%$ in $1 ; 11.6$. Only $3 \%$ of these -en forms are used target like, i.e. in 1./3.pl. contexts. Thus, the decrease of target like inflection in 1;11.6 probably can be explained by a spurt of the verbal lexicon. However, with the emergence of a default-form, verbs start to clearly denote a special class of concepts (cf. Tomasello 1992). They are now separated from the other parts of speech.

It is worth mentioning that Anna - in contrary to the Russian child - doesn't use imperatives very frequently. Instead, she mostly uses the -en form for expressing requests, wishes and demands. Up to the end of the investigated period it is the most frequent among the forms used non-target like. The most frequent inflected form which is used non-target like is the $-t$ form. As with all other forms, there is a high percentage of occurrences of $-t$ forms in contexts where no determination of target grammatical categories is possible (i.e. in most of the utterances lacking a subject phrase). Beyond that, $-t$ forms often occur non-target like when a completed event or action is expressed (cf. Bittner 2003b). Non-target use of other inflected forms (i.e. of $-e$ and $-s t$ forms) is hardly ever observed.

After 1;11.6 the proportion of non-target like -en forms diminishes. More and more verbs are used in a second or third inflectional form. The child enters the protomorphological (Dressler \& Karpf 1995, Bittner et al. 2003) or analogical (Tomasello 2001) phase. Inflectional contrasts are going to be acquired. The order in the acquisition of verb inflection by Anna can be described shortly as the following: as has been shown by various studies for being typical in German verb acquisition - the most salient (infinitive) form in -en is established as the dominant or default form of the verb after rote-learning. The development of verb inflection starts with the opposition of non-inflected (infinitive) forms in -en and $-t$ forms for 3.sg.pres The next step is to establish the correlation of $-\varnothing$ (stem) and $-e$ forms with 1.sg.pres followed by the acquisition of modal verbs which show $-\varnothing$ in 1./3.sg.pres. Regular use of $-s t$ for 2.sg.pres and -ge-Prefix for past (perfective) participles is a relatively late step mastered only after 2;2. In 1./3.pl.pres, the target form in -en occurs nearly without exception from the very beginning. However, this is related to its status as the default form. Plural contexts are comparatively infrequent in the data; 2 .pl contexts couldn't be observed at all. Past forms only 
occur in 1./3.sg with the auxiliary war 'was' and with -te in single modal verbs (woll-te 'wanted'). Past is mainly realised by periphrastic perfect constructions (hat (ge-)schlafen 'has slept'; ist auf(-ge-)wach-t 'was waking up') which are used more regularly only after $2 ; 1$.

\subsubsection{Inference: Vanja and Anna}

Both children are performing inflectional spurts in their speech production. Inflectional spurt with Vanja coincides with the spurt in VU. With Anna inflectional spurt clearly follows the VU spurt; in her data VU continuously amount more than $50 \%$ after 1;11.6. Thus - regarding the order of both spurts as well as the percentages of their peaks - we can conclude that inflectional development proceeds more quickly and comes nearer to adult-like performance in the Russian data than in the German data. This is especially remarkable because the German child shows continuous use of VU as well as an increasing verb lexicon earlier in time and in a considerably greater amount.

\subsubsection{Analyses III: Development of utterance complexity}

In order to investigate the impact of the acquisition of the verb and its inflectional properties on the development of utterance structure we now come to analyse syntactic properties of VU.

We first investigated the emergence of syntactic components ${ }^{13}$ within VU and conducted quantitative analyses in counting the total number of syntactic components per utterance irrespective of their structural quality, i.e. each syntactic phrase (e.g. potential subject and objects, predicate, adverbials, negation, deictic particles, etc.) was counted as one component. We distinguish three types of VU: one-component VU, i.e. VU containing only the verb (predicate); two-component VU, i.e VU containing the verb (predicate) and one further syntactic component; and multi-component VU, i.e. VU containing the verb (predicate) and more than one further syntactic component. Second, we analysed the development of verb inflection in each of these types of VU in order to examine the correlation of development in syntax and in verb inflection.

\subsubsection{Vanja}

The general proportion of the three types of VU changes over the investigated period in the following way (see Fig. 3a): one-component utterances clearly dominate, and only a few instances of multi-component utterances occur before the inflectional spurt. By the onset of the inflectional spurt and during it, one- and two-component VU are equalling up to $42 \%$ $44 \%$ and the number of multi-component VU reaches $15 \%$. This proportion changes after the spurt and remains relatively stable during the next three months: two-component VU take the leading position with around $40 \%^{14}$; they preponderate, except for $2 ; 4$, one-component VU by $6-9 \%$ while multi-component VU stay at the level of about $20 \%$ of all VU. The correlating tendency between multi-component and one-component VU during the last months may be seen: the former type increases by max. $26 \%$ and almost equals the latter one, which decreases up to $28 \%$.

\footnotetext{
13 'Component' refers to a major category term such as subject, verb, object, negation, etc.

14 Bloom (1994) points to the explanation of the continuous use of two-component utterances when children already are able to produce multi-component utterances as causalities of performance - in effect, linguistic mistakes, given in Brown (1973) and Bowermann (1973). Bloom himself postulates 'that the length of child utterances is systematically related to several linguistic factors and that this variation reflects linguistic competence'.
} 


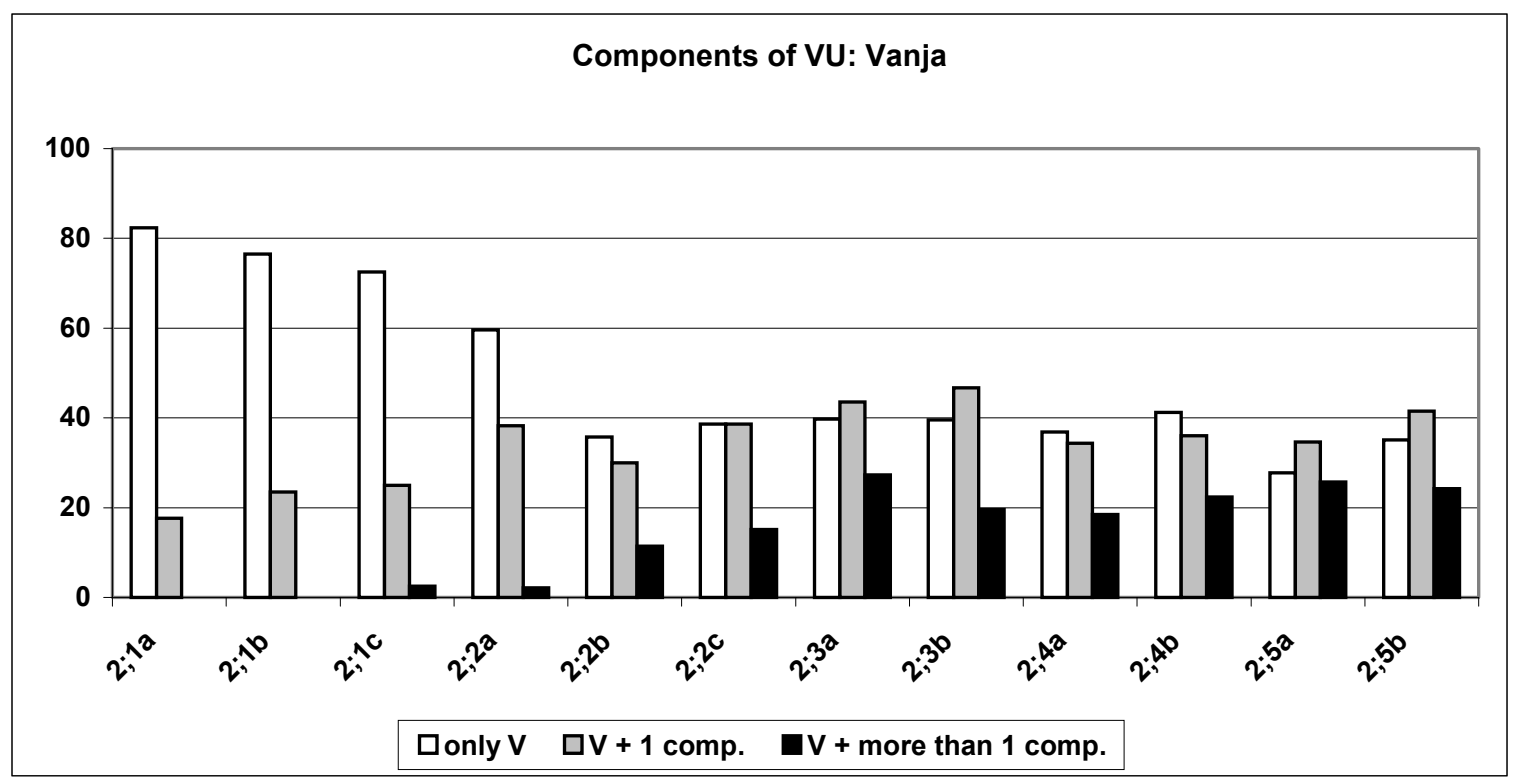

Fig. 3a. Disposition of one-, two, and multi-component VU

\section{Types of verb forms in one- and two-component $V U$}

Up to the age of $2 ; 2$ a one-component VU contain mainly imperatives and infinitives, like in the examples 1a-1c:

(1a) risuj, (baba)

draw-imp grandmother

(1b) (baba),

idi

grandmother go-imp

(1c) pomyt'

wash-inf (intention to wash)

Generally, the number of correct uses of finite forms in this type of VU repeats the inflectional spurt, see Fig. 3a'.

There are only a few two-component VU containing finite forms in the onset month of verb production, examples $2 \mathrm{a}-2 \mathrm{c}$. Along with the inflectional spurt, data show a spurt in the use of two-component VU with finite forms from $5 \%$ to $60 \%$. After the inflectional spurt the number of correctly used inflected forms in this type of VU does not undergo crucial changes except for the 2;4a session when Vanja, being recorded during home routine, used the high amount of imperatives, because his grandmother did not want to give him desirable toys.

(2a) poexal tuda

go-pf.past.masc.sg by car there

(2b) ushla mama

go-pf.past.fem.sg by foot mother

(2c) jagody daj

berries-acc give-imp 


\section{Multi-component $\mathrm{VU}$}

While the developmental use of two-component VU coincides with the general development of finite forms, multi-component VU seem to require a higher level of performance of verb inflection. Only isolated instances of multi-component VU, predominantly with imperatives, emerge before the inflectional spurt. This type of VU increase after the spurts in the amount of VU and target verb inflection: at the age of $2 ; 2 b$ and $2 ; 2 c-19$ and 45 instances respectively. After 2;3a the number of multi-component VU reaches 108 (47\%). Mainly inflected forms and, to a lesser extent, imperatives are used in multi-component VU, examples 3a-3d:
(3a) $2 ; 2 b$
Baba,
risuj
Vanje
eto
(grandmother)
paint-imp
vanja-dat
this
(3b) $2 ; 2 \mathrm{c}$

\section{Slomal}
vot zdes' tozhe
break-pf.past.masc.sg
here
also
(3c) $2 ; 2 \mathrm{c}$
Slomal
Vanja
koljosa
break- pf.past.masc.sg vanja
wheels-pl:acc
(3d) $2 ; 6 b$

$$
\begin{array}{ll}
\mathrm{Ja} & \text { priexal=piexij } \\
\text { i-sg.nom } & \text { come-pf.past.masc.sg }
\end{array}
$$
uzhe $=u z e$
already

What is important to mention here is that the spurt in the production of multi-component VU takes place after the inflectional spurt and along with the further increase of the use of VU and the development of the productivity in the production of finite forms.

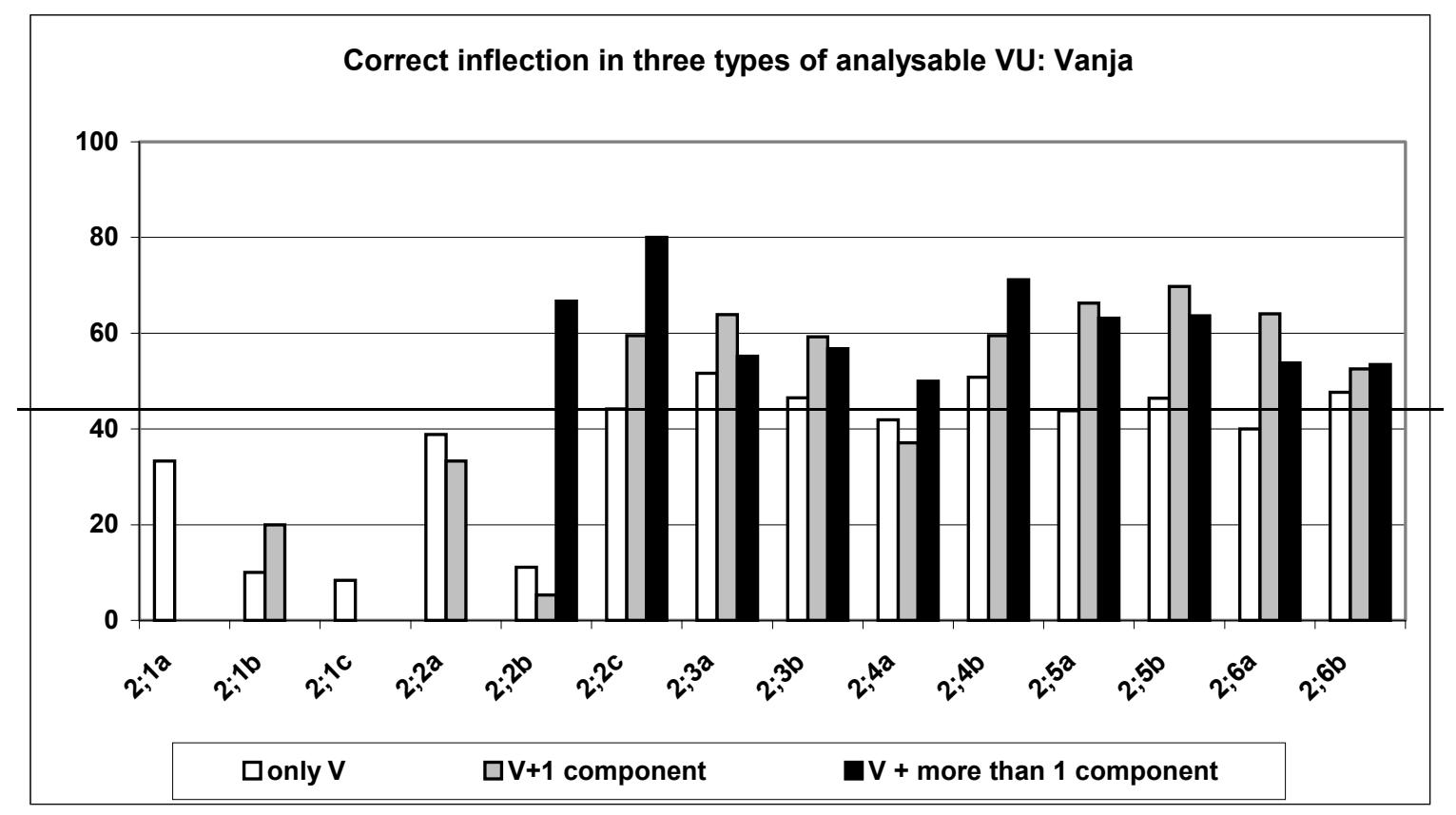

Fig. 3a'

15 The sign '=' means that V.'s pronunciation of a word (notably) differs from the normative one. The normative variant is given before the sign and its equivalent in child's speech after the sign '='. 
To recapitulate shortly: as we expected, inflected forms in VU containing only the verb basically resembles the development of the correct use of finite forms (see Fig. 2a) with one peculiarity. After the inflectional spurt their number remains under the level of $52 \%$ and does not crucially change anymore.

In two-component VU the number of correctly inflected verb forms, although generally behaving like in one-component VU, exhibits a higher level after the inflectional spurt (almost $70 \%$ at $2 ; 5 \mathrm{~b}$ ) and does not significantly change afterwards. ${ }^{16}$ And, finally, in the multi-component VU, correctly target-like inflected forms do not undergo significant changes and fluctuate between $50 \%$ and $70 \%$ from the onset of the use of this type of VU. ${ }^{17}$

\subsubsection{Anna}

In the first recordings one-component VU (examples 4a-4c)) clearly dominate, twocomponent VU (examples 5a-5c) are established but comparatively infrequent, and multicomponent VU (examples 6a,6b) only start to appear $(1>3>3$ instances in the first three recordings):

(4a) $1 ; 8.10$

bauen

build-inf

(4b) $1 ; 8.29$ hustet

cough-pres.3.sg

(4c) $1 ; 9.14$ abbeißen

bite up-inf

(5a) $1 ; 8.10$

Anna helfen

(instead of hilft)

anna (-agens) help-inf

help-pres.3.sg)

(5b) 1;8.29 alle kaputtgegangen=puttgangen

all broken down-*perf:part

(5c) 1;9.14 mütze aufsetzt

(instead of setze auf or habe aufgesetzt)

hat put on-pres.1.sg

(6a) $1 ; 8.10$

der hat

(einen

Helm)

auf

der-pron.masc

have-pres.3.sg (a-indef.pron.acc.sg helmet

on

(6b) 1;8.29 hier musik macht

here music do-pres.3.sg

\footnotetext{
16 Except for the recordings at 2;4a, when Vanja is engaged in a monotonous activity (playing with cars) produces similar sentences during the longer period.

17 By the end of the recordings, due to the increased number of finite forms with unclear inflectional endings, the number of correctly used clear forms automatically decreases slightly.
} 
At 1;9 and 1;10.0, the proportion between one- and two-component VU starts to change. Onecomponent VU decrease whereas two-component VU increase. For a short period a nearly equal proportion of both types is registered. After 2;0.5, one-component VU are used more and more rarely and become the most infrequent type of VU. In contrast, no clear decrease is attested with the two-component VU. More or less, they stabilise between $30 \%-40 \%$ of VU. The decrease of one-component VU is mirrored by the increase of multi-component VU. After 2;0.5 that type tends to become the most frequent type of VU, cf. Fig. 3a.

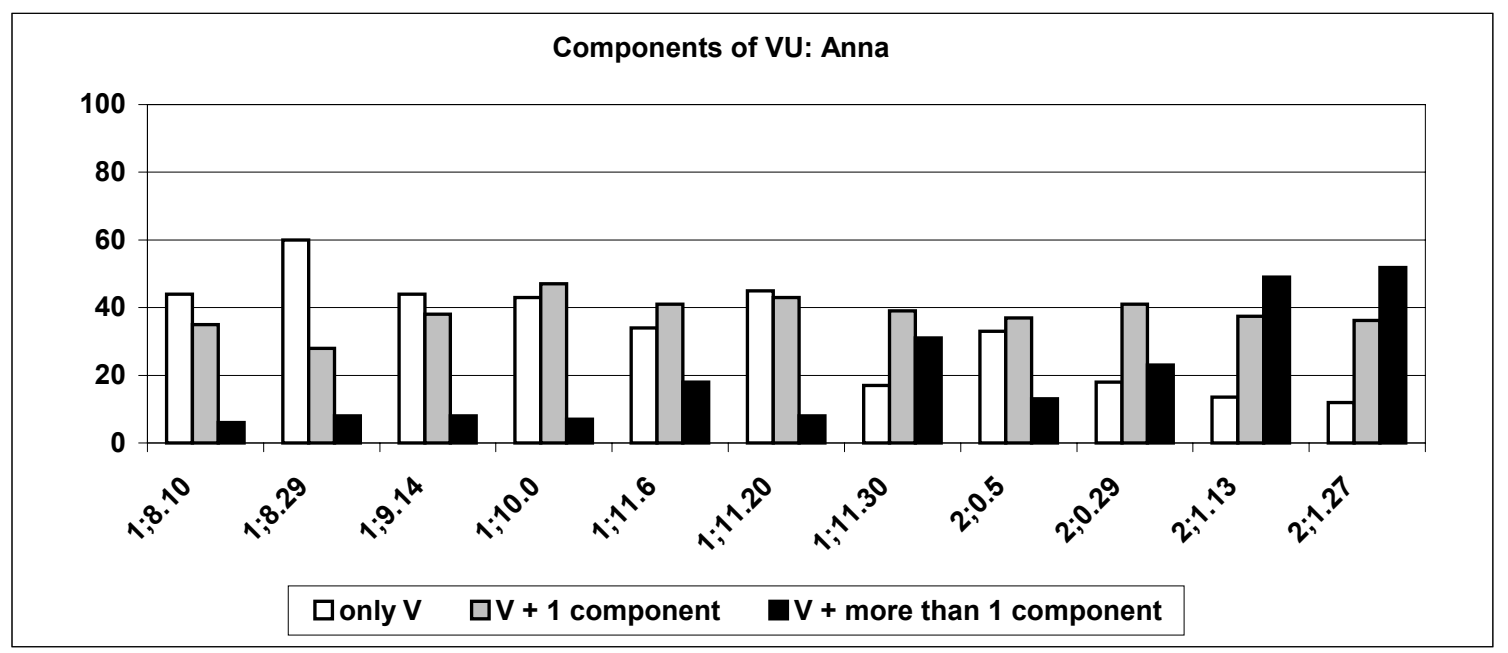

Fig. 3b. Disposition of one-, two, and multi-component VU

The development of syntactical complexity shows some correlation with the development presented in analysis I and II. The first change in the proportion of one- and two-component VU appears in 1;11.6 (accompanied by a slight increase of multi-component VU), i.e. when we observed the first spurt of VU and of new verb lemmas (Fig. 1b and Table 1b). The first steep spurt of multi-component VU is attested simultaneously with the first inflectional spurt in 1;11.30. Dominance of multi-component VU starts with the second inflectional spurt in $2 ; 1.13$ (Fig. 2a). The data suggest that the development of utterance complexity, especially the development of multi-component VU, is related to the acquisition of verb inflection. Fig. $3-1 b$ shows the proportion of target like inflection in each type of VU.

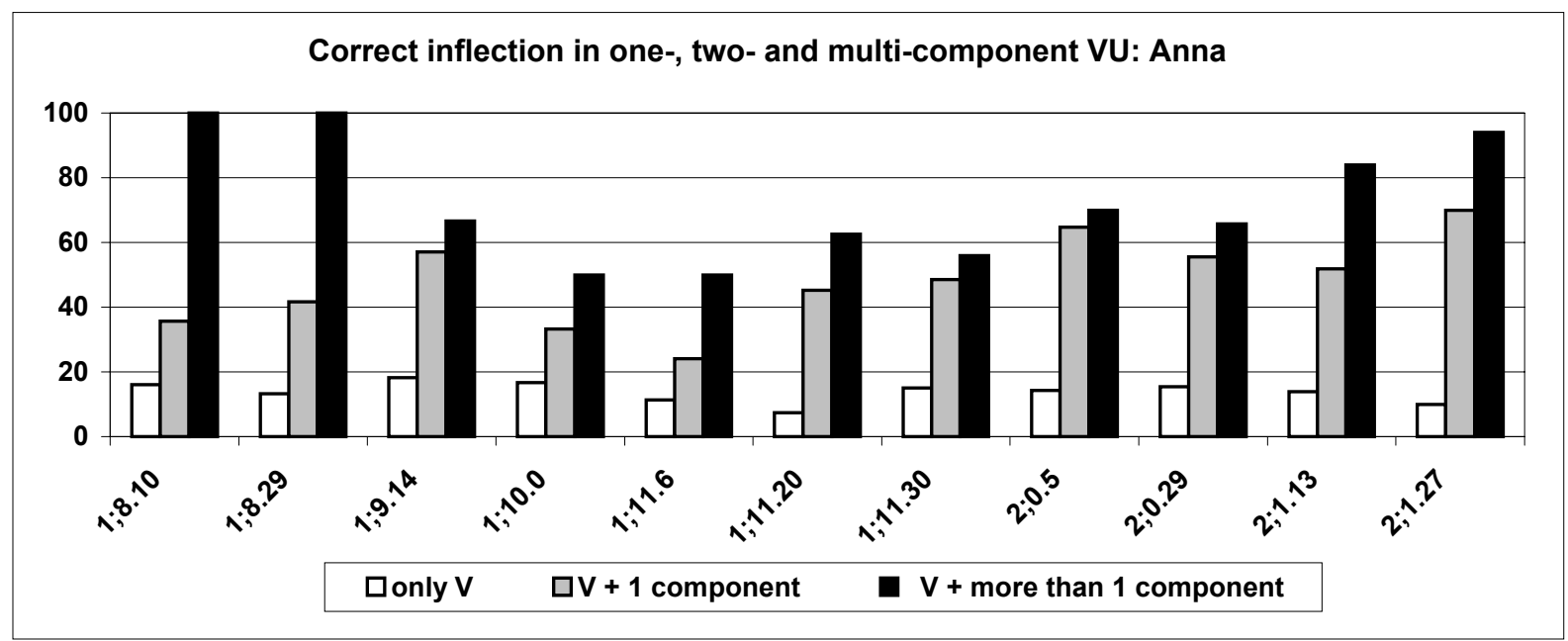

Fig. 3b'

One-component VU show low amount of correctly inflected verb forms. In the first recordings all inflectional types of verbs can constitute a one-component $\mathrm{VU}$, infinitive forms 
(bauen 'build', umdrehen 'turn round'), imperative forms (which are always frozen, guck 'look'), - $t$ forms (weint 'cryes', kommt 'comes'), as well as stem forms (mal 'draw', puttmach 'break'). However, the $-e n$ form is the most dominant verb type in these VU $(50 \%-70 \%)$. Furthermore, we observe an increase of $-e n$ forms in the last recordings. This means that inflected verb forms tend to disappear from this type of VU. One-component VU are of infinite character.

In two-component $\mathrm{VU}$, the $-t$ form is frequent alongside with the -en form from the very beginning. The $-t$ forms mostly occur in the target person/number context. After 1;11.6, correct adult-like inflection steadily increases. The development of two-component VU nearly mirrors the overall development of verb inflection.

In multi-component VU, a clear dominance of target-like inflected verbs is documented from the very beginning. When the first remarkable amount of multi-component VU of 24 instances appears, correct inflected verb forms amount 50\% in 1;11.6. After 1;11.6, a steady increase in number and in correct verb inflection (up to more than $90 \%$ ) is documented. In language development of Anna, the inflectional spurt seems to demarcate an important step towards multi-component VU.

\subsubsection{Inference: Vanja and Anna}

With both children we find similarities in the general syntactic development of VU. Onecomponent VU first dominate. Two-component VU appear with a small lag after the onset of verb production, their number promptly increases and reaches the same level as the onecomponent VU before the spurts. These equal levels of the production of different types of VU remain for a certain period. Also, with both children, multi-component VU start very small in number and increase at the lowest rate. However, only with the German child multicomponent VU occur earlier and exceed the less complex types of VU. With the Russian child, the multi-component VU reach one fourth from the total amount of VU only by the last investigated month. As to the correct use of finite verbs, the most notable similarities were documented in multi-component VU: the majority of verbs attach correct inflection from the onset their production. The most remarkable differences were exhibited after the spurts in the use of correct finite verb forms in one-component VU: in German - about 15\%, in Russian between $40 \%$ and $52 \%$.

\subsubsection{Analyses IV: Emergence of potential subjects and potential objects in VU}

In this last section, we will conduct a quantitative analyses of the emergence of potential subjects, potential objects, and both, subjects and objects, in VU (henceforth, VU+S, VU+O and VU+SO).$^{18}$ Analyses of other grammatical features of these arguments in this early phase remains for further investigations.

\subsubsection{Vanja}

Among the three mentioned types of VU the one with objects occurs at first (at $2 ; 2 a$ ). Hoewever, a comparatively small group of the early two-component VU contain object whereas the dominating structure is $\mathrm{VU}+\mathrm{X}$. In the early $\mathrm{VU}+\mathrm{O}$, imperatives and infinitives constitute the absolute majority of the verb forms used, e.g. jagody daj 'berries give-imp", stroj vorota 'build-imp gates, risovat' gruzovik 'draw-inf lorry' ( $2 ; 2 \mathrm{~b})$, etc. After $2 ; 3 \mathrm{~b} \mathrm{VU}+\mathrm{O}$ containing a finite verb (and an omitted subject) start to preponderate over utterances with the non-finite verb forms, examples 7a,7b:

\footnotetext{
18 All types of syntactical phrases which are not directly verb dependent, i.e. prepositional phrases, adverbials, particles, negation and so on, are summarised under the label X or VU+X.
} 
(7a) $2 ; 3 b$

Dveri $=$ gevi

door-acc.pl $z a k r y l=a k i j$

close-pf.past.masc.sg

'(i) closed the doors'

(7b) $2 ; 4 \mathrm{a}$

$$
\begin{aligned}
& \text { Ochki=as'ki nadela=adeja } \\
& \text { glass-pl.acc put-on-pf.past.masc.sg } \\
& \text { '(she) put on the glasses' }
\end{aligned}
$$

VU with potential subjects occur by the age $2 ; 2 \mathrm{c}$ when, as we showed before, the stability in the proportion between VU with different number of components is established. In VU+S no dramatic changes in the correct use of finite forms are observed and this type of VU holds the consistent preponderance over $\mathrm{VU}+\mathrm{O}$ (except 2;4b when Vanja produces a lot of imperative VU with O) shortly after it emerges. The steepest increase of VU+S from $10 \%$ to $19 \%$ is noted between $2 ; 2 \mathrm{~b}$ and $2 ; 2 \mathrm{c}$. It coincides with the spurt in the production of finite forms and seems to be in interaction with this spurt. The acquisition of agreement features and spurt in the production of finite forms provides the base for the further development of VU+S. After $2 ; 2 \mathrm{c}$ the number of $\mathrm{VU}+\mathrm{S}$ reaches $19,4 \%$ and does not change significantly anymore staying at the level of about $20 \%$.

So, to recapitulate shortly: utterances with potential objects emerge before the inflectional spurt and contain mainly imperatives. The first steps in the acquisition of potential subjects clearly start along with the inflectional spurt which happens between $2 ; 2 \mathrm{~b}$ and $2 ; 2 \mathrm{c}$. After inflectional spurt VU+S remain at the level of around $20 \%$ and $\mathrm{VU}+\mathrm{O}$ oscillate between $11 \%$ and $22 \%$.

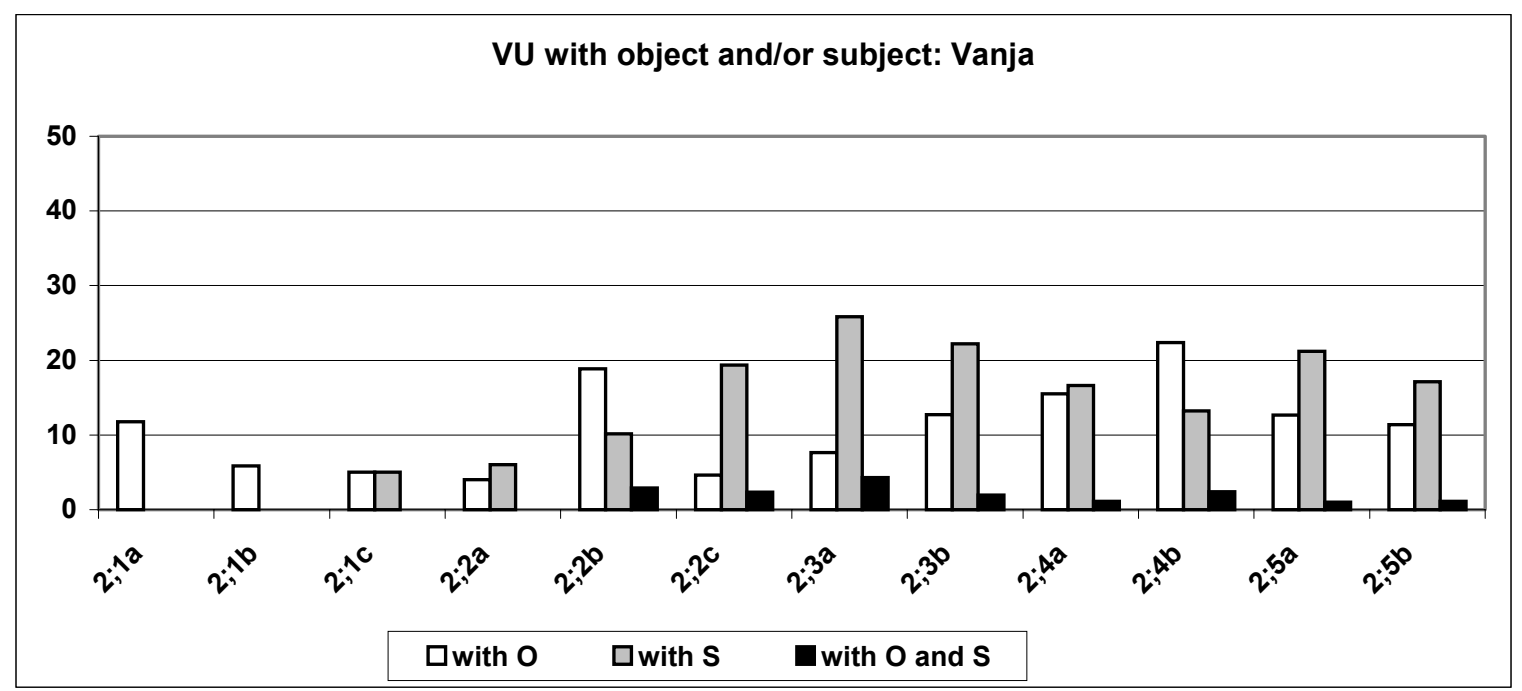

Fig. $4 \mathrm{a}$

The first instances of $\mathrm{VO}+\mathrm{SO}$ occur at the age of $2 ; 2 \mathrm{~b}$ and increase considerably by $2 ; 3 \mathrm{a}$ after inflectional spurt and the onset of the productive use of finite forms, example (8):
(8)
2;3a slomal
dveri
djadja 
break-pf.past.masc.sg man-nom

'The/a man broke the doors'

However, these VU remain under 4,3\% over the whole period investigated, sometimes come close to disappearing. As soon as Vanja learns to use finite verbs productively - and this takes him about two months (cf. Fig.2a) - he starts to omit (pro)nouns in the subject position, which is possibly due to the pro-drop peculiarity of Russian, example 9 (and 7a,7b):

$$
\begin{array}{lll}
2 ; 4 \mathrm{a} & \text { tort } & \text { el } \\
& \text { cake-acc } & \text { eat-ipf.past.masc.sg }
\end{array}
$$

'(i) was eating the cake'

Thus, VU+SO had hardly begun to develop when they disappear again. Such 'backwards' development takes place after the inflectional spurt.

\subsubsection{Anna}

Though potential subjects are more frequent than potential objects in the first recording we would claim that in the German data, like in the Russian data, there is a preference for $\mathrm{VU}+\mathrm{X}$ (examples 10a,10b) and VU+O (example 10c) before the inflectional spurt.

$$
\begin{aligned}
& \text { (10a) hinhocken bißchen } \\
& \text { squat-ing a bit } \\
& \text { 'squat down a bit' } \\
& \text { (10b) hier raufsetzen } \\
& \text { here sit-down-on-inf } \\
& \text { 'sit down on here' } \\
& \text { (10c)tuch abmachen } \\
& \text { scarf take-off-inf } \\
& \text { 'take off the scarf' }
\end{aligned}
$$

The higher amount of potential subjects in the beginning of the recordings can be related to a frequent use of proper names in these recordings. ${ }^{19}$ As Fig. $4 \mathrm{~b}$ shows, the preponderance of $\mathrm{VU}+\mathrm{O}$ decreases during the inflectional spurt. In the final phase of the inflectional spurt the use of VU+S (examples 10d,10e) suddenly and steeply increases by nearly $30 \%$ and notably exceed VU $+\mathrm{O}$. From now on, around $40 \%$ of all VU include a potential subject. VU+O continually regress and finally fall under the growing amount of VU+SO. VU containing both a potential subject and a potential object starts to occur only after the inflectional spurt. At $2 ; 05$, the first considerable quantity (6 instances) is used. Like in the Russian data, we find that it takes the child more time to acquire the combination of these two verb-dependent syntactic phrases than the combination of one of them with another verb-independent phrase (cf. the occurrence of multi-component VU in Fig. 3a and b).

19 Recall that Anna was not recorded by her mother, thus there is a phase of becoming familiar with the situation of intensively interacting with the interviewer. 
(10d) $1 ; 11.30$ wir beide malen

we both draw-pres.1.pl

'we both are drawing'

(10e) $2 ; 0.5$ ein bein fehlt

a leg miss-pres.3.sg

'a leg is missing'

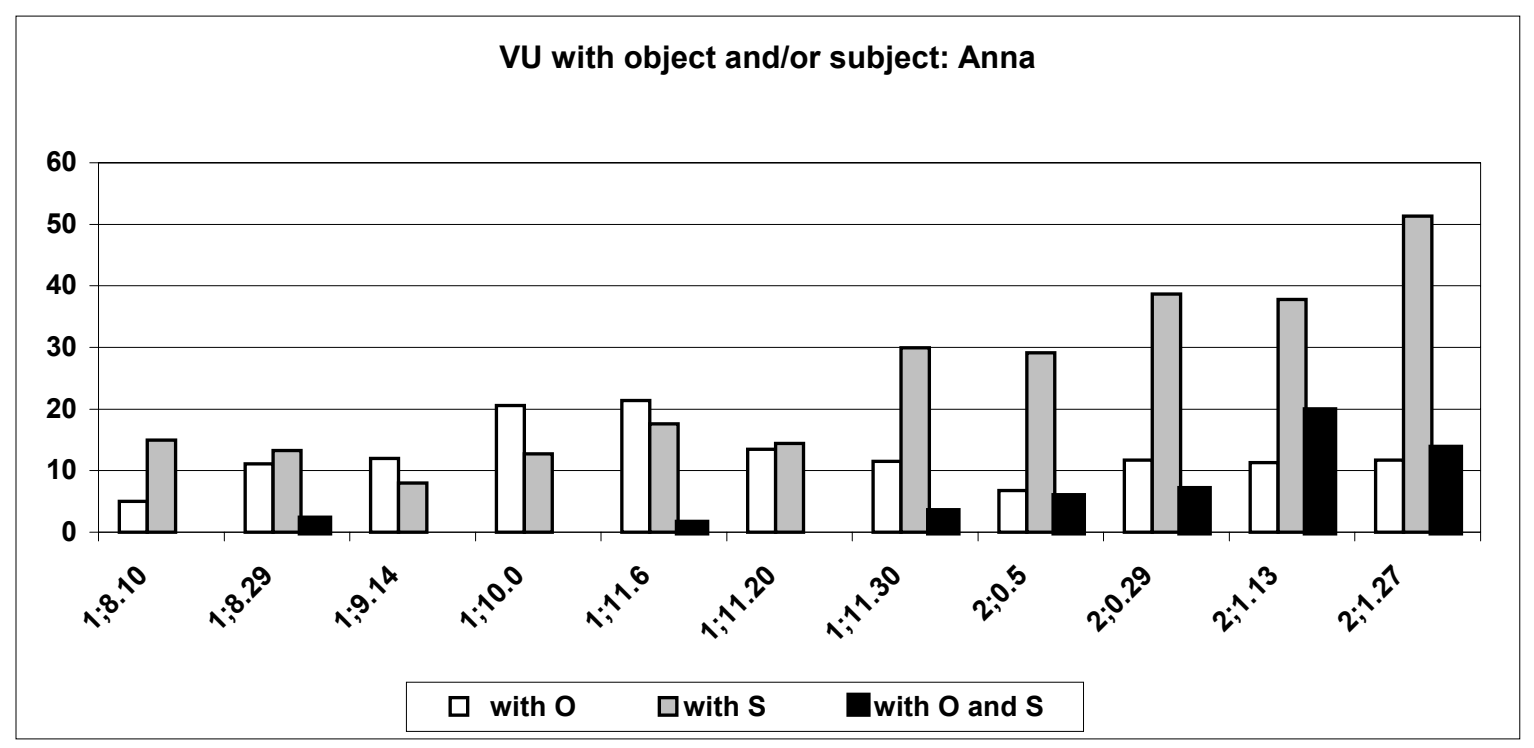

Fig. $4 b$

In the construction of multi-component VU, a strong preference for potential subjects is given from the very beginning. It appears in the combination with a temporal or local adverbial, the negation particle nicht 'no' or the modal particle auch 'too'. During the last recordings, combination of potential subject and potential object becomes frequent, cf. ich hab ein taschentuch 'I have a handkerchief', das krokodil frißt dich auf 'the crocodile eats you up'. VU+SO nearly never occur with a non-target-like inflected verb.

\subsubsection{Inference: Vanja and Anna}

$\mathrm{VU}+\mathrm{O}$ and $\mathrm{VU}+\mathrm{S}$ occur in both children before $\mathrm{VU}+\mathrm{SO}$ almost together with the onset of (finite) verb production. VU+SO occur also similarly in both children: after inflectional spurts have taken place. The order of emergence of VU with either $\mathrm{O}$ or $\mathrm{S}$ differs in two children: while Vanja starts with the production of VU with O, Anna has utterances with S and O from the onset of the analysed period with general prevalence of the latter. Another interindividual variation manifests itself in the number of VU+SO: aside from the fact that Vanja generally produces less VU of this type, their amount does not exceed the maximal level of $4,3 \%$ at 2;3a. Moreover, the amount of these VU slightly decreases later on. In contrast, Anna uses VU+SO more actively, gradually increasing their amount up to $16,8 \%$ at $2 ; 1.13$.

\section{Discussion}

We group the first two and the latter two analyses and discuss them subsequently. Within the analyses I and II we investigated the emergence and the development of utterances containing 
verbs and the acquisition of the correct finite verb forms. The (correlated) increase in documented new verb lemmas and in the number of VU seems to reflect a developmental interrelation between these two processes, although verb lemmas documented in the recordings do represent only a part of the full verb lexicon of each child. This becomes very clear with the development of Vanja. Before the emergence of the first verbs in his lexicon he denotes various actions by dat' 'give', e.g. switch off the light, open the door, etc. Gradually, target-language verb forms start to be assigned to perceived situations and performed routines more specifically (what we called the 'onset' of verb production) and after a short period VU increase significantly (VU spurt). This spurt in VU starts together with the inflectional spurt and precedes the spurt in new verb lemmas. In the period of ten days, VU doubles from $13,8 \%$ to $27,9 \%$ of all utterances, and correct finite forms increase from $16 \%$ to $56 \%$; afterwards verb lemmas start to increase rapidly (26 new lemmas at 2;3a, followed by 39 at $2 ; 3 b$ and 35 at $2 ; 4 a)$.

A different course of spurt is observed in Anna: the spurt in VU and new lemmas precedes inflectional spurt. With Anna the simultaneity of the verb lemma spurt and VU spurt in 1;11.6 underlines the strong correlation of both processes (Table 2). As has been shown in Bittner (2000/2003a), the diversity of inflectional forms increases at the same time. Whereas nearly only $-e n$ and $-t$ forms are used before $1 ; 11.6,-\varnothing$ and $-e$ forms, and past participle forms become frequent afterwards. Thus, besides the increase in verb lemmas correlated by the establishing of the -en form as the default form of the verb, verb inflection is going to change to a new quality, which results in the steep increase of target-like inflection after 1;11.6 (Fig. $2 b)$.

Irrespective the fact that a spurt in verb lexicon is difficult to manifest unambiguously in this kind of data, we can assume that a certain critical mass of verb lemmas has to be acquired in order to raise VU to a certain quantitative level where the verb-centred type of utterances can become structural relevance (cf. Lyons, Teer, \& Rubenstein 1978, Marchman \& Bates 1994). As one can see in Fig. 1a as long as Vanja uses the only protoverb dat' VU remain only a marginal type of utterance in his speech. Only after more than 50 different verb lemmas have been documented in his lexicon, VU reach one-third of all utterances. With Anna, 40 verb lemmas are documented already in the second recording - and the amount of VU in relation to all utterances composes one-third. Anna's spurt of VU up to more than 50\% happens after the number of documented verb lemmas has increased rapidly from approx. 70 to more than 100 .

Table 2. Outline of the spurts

\begin{tabular}{|c|c|c|}
\hline & Vanja & Anna \\
\hline First verbs/first recording & $2 ; 1 \mathrm{c}$ & $1 ; 8.10$ \\
\hline Spurt in VU & $2 ; 2 \mathrm{~b}-2 ; 2 \mathrm{c}$ & $1 ; 9.14-1 ; 11.6$ \\
\hline Spurt in verb lemmas & $2 ; 2 \mathrm{c}-2 ; 3 \mathrm{a}$ & $1 ; 10.0-1 ; 11.6$ \\
\hline Inflectional spurt & $2 ; 2 \mathrm{~b}-2 ; 2 \mathrm{c}$ & $1 ; 11.6-1 ; 11.30$ \\
\hline
\end{tabular}

On the one hand, we find a narrow time correlation in three types of spurts in the emergence of VU, of verb lemmas, and of correctly used finite verbs with both children. On the other hand, the order of spurts varies between the two children. Further, the character of the emergence and development of verb inflection appears to be different. Most probably this can be explained by the language specific properties of verb inflection mentioned in section 1.2. The faster development and the higher degree of mastering verb inflection by the Russian boy seems to be related to the clearly distinct marking of each person/number category in present and each gender/number category in past forms including the clear inflectional distinction of the (synthetic) present and past. There is no homophony in the system, hence the form- 
function correlation is relatively salient and easy to access to the child. Besides, the analytic verb constructions with auxiliaries do not take such a significant place in the verbal morphology and do not play such a crucial role for the acquisition of verb inflection in Russian as they do in German. The lexical and grammatical meaning is overwhelmingly compiled in one verbal lemma (except for the imperfective future). All these languagespecific features result in a different degree of accessibility of the target functional load of inflectional affixes and thus in an earlier and more rapid spurt of target verb inflection in Russian vs. a slightly later and weaker spurt in German. Nevertheless, in both children the processes resulting in the spurts in VU and verb inflection are tightly connected and we assume that this may be a general developmental pattern.

The fairly plausible assumption that an inflectional spurt is a prerequisite of an increase in VU is ruled out by the slight differences in the order of the spurts in the emergence of VU and (correctly used) finite forms. With Vanja, the inflectional spurt first precedes and then overlaps with the spurt in VU. With Anna, the spurt in VU precedes the inflectional spurt.

The analyses III and IV deal with the number (one-, two-, and several) and types (object, subject, and object+subject) of components in VU. With both children, one-component VU prevail at the beginning and gradually diminish later, but they are not absolutely superseded. In Russian, their amount after the inflectional spurt stays between $28 \%$ and $40 \%$. In German, the amount of one-component VU after the inflectional spurt fluctuates between $10 \%$ and $20 \%$, which is probably comparable to their use in adult speech. With the German child, the reduction of one-component VU and parallel decrease of two-component VU starts before the inflectional spurt. However, the first dramatic change in the proportion of the three types of VU arises in the period of the inflectional spurt. At 1;11.30, the amount of one-component VU lies under the amount of two- and multi-component VU for the first time, and the amount of multi-component VU steeply increases and goes beyond the two other types. To put it another way, after 1;11.20, when the inflectional spurt has started, the proportion of the three types of VU varies up to the point in development at which the amount of correct adult-like inflection approaches to the $60 \%$ (at $2 ; 1.13$ ) and multi-component VU becomes the dominating type of VU. With both children, changes in syntactical development are temporarily linked with the inflectional spurt. The correlation is stronger with the Russian child where we find the reduction of one-component VU and clear increase of multicomponent VU from $2 ; 2 \mathrm{a}$ to $2 ; 2 \mathrm{c}$.

We suppose that the development of two-component VU represents primarily the growing ability to combine two syntactical elements, which is also observable in the development of utterances without verbs. As Fig. 3a' and 3b' show, the proportion of adult-like inflected verbs in two-component VU decreases after 1;9.14 in the German data and after 2;2a in the Russian data. This is the point in development at which the number of verb lexemes and twocomponent VU spurts (tables 1 and figures 3 ) and the period of rote learning of inflected verbs finished. The amount of correctly inflected verbs in two-component VU is rather low at this time but increases soon, whereas no such increase is documented in the one-component VU. In multi-component VU correctly inflected verbs are dominant from the very beginning. Thus, acquisition of verb inflection and acquisition of two-component VU appear closely related and interplaying.

Finally, in the emergence of multi-component VU, we find similarities as well as the most notable differences with both children. In the Russian and in the German data the use of multi-component VU steeply increases only after the inflectional spurt. Before the inflectional spurt has reached its peak, i.e., at 1;11.30 in German and at 2;2c in Russian, only non-regular occurrences of multi-component VU are documented. At the peak of inflectional spurt multicomponent VU come to $39 \%$ in German and to $15 \%$ in Russian. As mentioned above, it 
seems that the combination of the verb with two further syntactical phrases requires the acquisition of verb inflection, or to put it more generally - the acquisition of grammatical features of the verb. The steep increase in the number of multi-component VU may be seen as the consequence of the acquisition of finiteness, which opens an access to the broad 'linking' of a topic component to a sentence base within a child's utterance and allows a child the production of this type of utterances.

Differences between both children appear in the development after inflectional spurt. In the Russian data the amount of multi-component VU remains at a level of around $20 \%$ except for the last month, i.e., consistently lower than that of one- and two-component VU. In the German data, in contrast, a further spurt is observed. When adult-like verb inflection reaches $60 \%$, the amount of multi-component VU increases to $50 \%$, which is the highest proportion among the three types of VU. Since the majority of multi-component VU in our data relate to the SVO type we comment on this empirical finding below.

Our study shows that the complexity of utterances starts to develop after the lexical and inflectional verb spurts have taken place. The question arises here, whether this is just a codevelopment or, to certain extent, the linked development of morphological and syntactical systems (increase of the complexity of VU and occurrence of VU with $\mathrm{S}$ and $\mathrm{O}$ ). Let us address the issue of the emergence of verb dependent and correlated components within twoand three-component sentences.

In both children, VU with S or O occur before spurts: Vanja and Anna preferred, with some quantitative differences, VU with $\mathrm{O}$. The priority in the early production of VU+O with Vanja and Anna may be explained by several factors: the child needs minimum verb inflection to construct such VU - one may use direct object not only with inflected verbs, but also with imperatives and infinitives, that are rather frequent at least in Vanja's data until 2;1b. Another, pragmatic factor is the necessity of naming the desirable and perceived object, which is also important on the early stages of language acquisition (Clahsen 1982). Thus, such sentences do not need verbal agreement, but only accusative case marking, which is, in some cases, the same as nominative.

Both children are similar in that SVO sentences start to be used regularly during or after the inflectional spurt, which means that having only 'mastered' a certain number of inflected verb forms, children went on further in increasing the complexity of VU. The analyses of the development of VU+SO given in Fig. 4a allows the following (very preliminary) hypotheses:

In relation with the inflectional spurt the child first - via agreement and finiteness - learns that inflected verbs require a subject phrase

Thus, with Vanja, for example, potential subjects in VU rise considerably up until 2;3a, both in two- and in multi-component VU. Having acquired productive verb inflection and finiteness, the child learns that verb inflection suffices to assign the subject referent. Thus, subjects start to be notably omitted due to a language specific property after 2;3a. This omission raises the difference in the number of SVO structures produced by children. Anna's use of SVO sentences steadily increases, while Vanja's use - having increased by the age of $2 ; 3$ a by about $6 \%$ - dramatically decreases afterwards and does not exceed the level of $5 \%$. Again, language specific and individual reasons may underlie such a situation. First, as mentioned above, Russian allows the use of sentences with omitted subjects (see Nilsson 1982, Frank 1994, etc.) as in the conversation between Vanja (at the age 2;3b) and his grandmother in (11) below: 
(11)

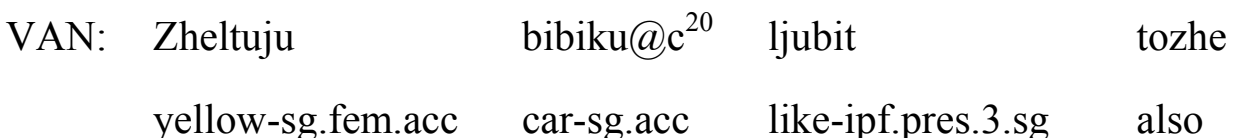

'(He) also likes the yellow car'

BAB: Chto?

what

VAN:Bibiku@c

ljubit

tozhe

car-sg.acc like-ipf.pres.3.sg also

'(He) also likes the car'

\%sit: Grandmother doesn't understand

VAN:Bibiku@c ljubit Vanja tozhe

car-sg.acc like-ipf.pres.3.sg vanja also

'Vanja also likes the car'

BAB: Ax bibiku ljubish'?

ah, car-sg.acc like-ipf.pres.2.sg

'Ah, (you) like the car?'

VAN: Da.

yes

It is interesting to note that the grandmother - having not understood the child due to the omitted subject - also uses subjectless construction in her own commentaries on the utterance of Vanja. Second, Vanja's speech is strongly influenced by the numerous questions of his grandmother, who almost always initiated his speech production.

Generally, the impact of language specificity is most significantly displayed in the production of SVO sentences.

\section{Conclusion}

We observed several differences and similarities in the development of verb inflection and sentence complexity in the first language acquisition of Russian and German.

Variation in the developmental frame exhibited at the level of the verb (inflection) and the utterance (sentence complexity) is caused by differences in the respective verb systems and sentence structure of Russian and German, i.e., language-specific properties, influencing the acquisitional process. For example, the pro-drop character of Russian induces the reduction of the number of VU with three or more overt syntactical phrases. The presence of copula constructions in German may slow down the acquisition of verb inflection (after the inflectional spurt) and influence the order of the spurts.

20 'Bibika' is the child-specific word for the adult mašina 'car'. 
Similarities in the developmental processes provide us with empirical evidence of the universal pattern manifesting itself in the correlation between the gradual development of verb inflection and the growing complexity in the construction of multi-component utterances with $\mathrm{S}$ and $\mathrm{O}$. We argue that the inflectional spurt is a prerequisite of the development of verb dependent arguments. And, generally, the finite verb (and finiteness) is a catalyst for syntactic development. Whereas this developmental course maybe considered to be universal (or, at least, common for the two languages observed), the sequences of the three spurts analysed in this study and, in particular, certain developmental changes after the spurts, are specific to Russian and German. Moreover, language specific differences start to manifest themselves with the onset of the crucial growth of the inflection of verbs and are exhibited most significantly in the production of multi-component VU and SVO.

In the present article we analysed the speech development of only one child per language; more data, of course, are needed in order to make hypotheses more valuable.

To sum up, we found in both children a common correlation between the emergence of finite verbs and their arguments. Language-specific variation manifests itself (in the order of development) within these two processes.

\section{References}

Avrutin, S. (1999): Development of the Syntax-Discourse Interface. Studies in Theoretical Psycholinguistics, Kluwer Academic Publishers.

Bar-Shalom, E. \& W. Snyder (1999): On the relationship between Root Infinitives and Imperatives in Early Child Russian. Paper presented at BUCLD 23: Proceedings of the 23rd Annual Boston University Conference on Language Development, Boston University.

Bittner, D. (2000). Early verb development in one German-speaking child. In D. Bittner, W. U. Dressler \& M. Kilani-Schoch (eds.): First verbs: on the way to mini-paradigms. ZAS Papers in Linguistics 18, 143-162.

- (2003a): The emergence of verb inflection in two German-speaking children. In: D. Bittner, W.U. Dressler, M. Kilani-Schoch (eds.): Development of verb inflection in first language acquisition. A cross-linguistic perspective, 53-88. Berlin: de Gruyter.

- (2003b): Aspectual interpretation of early verb forms in German. ZAS Papers in Linguistics 29, 3-25.

Bittner, D., W.U. Dressler, M. Kilani-Schoch eds. (2003): Development of verb inflection in first language acquisition. A cross-linguistic perspective. Berlin: de Gruyter.

Bloom, P. (ed). (1994): Language acquisition: Core readings. Cambridge, MA: MIT Press.

Bloom, L., Lifter, K. \& Hafitz, J. (1980): Semantics of the verbs and the development of verb inflecrtion in child language. Language 56, 386-412.

Bowerman, M. (1973): Early syntactic development: A cross-linguistic study with special reference to Finnish. Cambridge: Cambridge University Press.

Bronkart, J-P. and Sinclair, H. (1973): Time, tense and aspect. Cognition 2, 107-30.

Brown, R. (1973): A First Language. Cambridge MA: Harvard University Press.

Ceytlin, S. N. (2000): Jazyk i rebjonok: Lingvistika detskoj reči. Moskva: VLADOS. [The language and the child: Language acquisition].

Clahsen, H. (1982): Spracherwerb in der Kindheit: eine Untersuchung zur Entwicklung der Syntax bei Kleinkindern. Tübingen: Narr.

- (1991): Child language and developmental dysphasia: linguistic studies of the acquisition of German. Amsterdam, Philadelphia: Benjamin.

Clahsen, H. \& Penke, M. (1992): The acquisition of agreement morphology and its syntactic consequences: New evidence in German child language from the SIMONE-Corpus. In J. M. Meisel (ed.): The acquisition of verb placement. Functional categories and V2 phenomena in language acquisition. Dordrecht/ Boston/London: Kluwer.

Comrie, B. \& G. Corbett (eds.) (1993). The Slavonic Languages. Routledge. 
Dressler, W. U. \& A. Karpf (1995): The theoretical relevance of pre- and protomorphology in language acquisition. Yearbook of Morphology 1994; 99-122.

Franks, S. (1995): Parameters of Slavic morphosyntax. Oxford University Press.

Gagarina, N. (2000): Early verb development in one Russian-speaking child. In D. Bittner, W. U. Dressler \& M. Kilani-Schoch (eds.): First verbs: on the way to mini-paradigms. ZAS Papers in Linguistics 18, 143-162.

- (2002): Thoughts on Optional Infinitives (in Russian). In D. Hole, P. Law, \& N. Zhang (eds): Linguistics by Heart, Webfest for Horst-Dieter Gasde. Berlin: ZAS, 1-23. <http://www.zas.gwzberlin.de/mitarb/homepage/webfest>

- (2003): The early verb development and demarcation of stages in three Russian-speaking children. In: D. Bittner, W.U. Dressler, M. Kilani-Schoch (eds.): Development of Verb Inflection in First Language Acquisition, 131-169. Berlin: de Cruyter.

Gagarina, N., Voeikova, M., \& S. Gruzincev (2003): New version of morphological coding for the speech production of Russian children (in the framework of CHILDES). In P. Kosta, J. Blaszczak, J. Frazek, L. Geist, \& M. Zygis (eds.): Investigations into Formal Slavic Linguistics. Contributions of the Fourth European Conference on Formal Description of Slavic Languages, University of Potsdam.

Gawlitzek-Maiwald, I., Fritzenschaft, A. \& Tracy, R. (1992): Language acquisition and competing linguistic representations: the child as arbiter. In J. Meisel (ed.): The acquisition of verb placement. Functional categories and V2 phenomena in language acquisition. Dordrecht/Boston/London: Kluwer.

Jakobson, R. (1984): Izbrannyje raboty. V.A.Zvegincev (ed). Moskva: Progress. [Selected writings]

Kiebzak-Mandera, D. (1999): Kształtowanie się systemu werbalnego u dzieci rosyjskojęzycznych: analiza porównawcza. Unpublished $\mathrm{PhD}$ Dissertation, Jagiellonian University. [The formation of the verbal morphology in Russian-speaking children: a comparative analysis]

Kiebzak-Mandera, D., M. Smoczyńska, \& E. Protassova (1997): Acquisition of Russian verb morphology: the early stages. In: W. U. Dressler (ed.): Studies in pre- and protomorphology, 101-114. Wien: Verlag der Österreichischen Akad. der Wissenschaften.

Loeb, D. \& Leonard, L. (1991): Subject case marking ad verb morphology in normally developing and specifically language impaired children. Journal of Speech and Hearing Research 34, 340-46.

Lyons, A., P. Teer, \& H. Rubenstein (1978): Age-at-acquisition and word recognition. Journal of Child Language 21, 339-366.

MacWhinney, B. (1995): The CHILDES project: tolls for analysing talk. Hillsdale, NJ: Erlbaum.

Marchman, V. \& E. Bates (1994): Continuity in lexical and morphological development: A test of the critical mass hypothesis. Journal of Child Language 21/2, 331-366.

Mueller-Garthercole, V. C., E. Sebastian, \& P. Soto (1999): The early acquisition of Spanish verb morphology. Across-the-board or piecemeal knowledge? The International Journal of Bilingualism 3, 133-182.

Nilsson, B. (1982): Personal pronouns in Russian and Polish: a study of their communicative function and placement in the sentence. Acta Universitatis Stockholmiensis. Stockholm Slavic Studies 13. Stockholm, Sweden: Almquist and Wiksell International.

Poupynin, J. A. (1996): Usvoenie sistemy russkix glagol'nyx form rebenkom. Voprosy jazykoznanija 3, 84-95. [The acquisition of the system of Russian verbal forms by a child]

- (1998): Elementy vido-vremennoj sistemy v detskoj rechi. Voprosy jazykoznanija 2, 102-116. [The elements of the system of tense and aspect in language acquisition]

Radford, A. (1990): Syntactic Theory and the Acquisition of English Syntax. Oxford: Basil Blackwell.

Rispoli, M. (1999): Case and agreement in English language development. Journal of Child Language 26, $357-$ 72.

Savosteenko, N. (1995): K postroeniju tipologii nacal'nyx detskix vyskazyvanij. In S. Ceytlin \& T. Krugljakova (eds.): Usvoenije reb'onkom rodnogo (russkogo) jazyka, 78-82. St. Petersburg, Akcident. [To the typology of the early children's utterances].

Tomasello, M. (2001): Thw Item-Based Nature of Children's Early Syntactic Development. In M. Tomasello, \& E. Bates (eds.): Language development: The essential readings. Malden, Mass./Oxford: Blackwell.

Verrips, M. \& Weissenborn, J. (1992): Routes to verb placement in early German and French: The independence of finiteness and agreement. In J. Meisel (ed.): The acquisition of verb placement. Dordrecht/Boston/London: Kluwer.

Voeikova, M. (2000): Russian existential sentences: A functional approach. LINCOM Studies in Slavic Linguistics. München: LINCOM Europa. 
Wade. T. (1992): A Comprehensive Russian Grammar, Blackwell.

Weissenborn, J. (1990a): Subjektlose Sätze in der frühen Kindersprache. Ein theoretisches und empirisches Problem der Spracherwerbsforschung. In: Der Deutschunterricht 42, 35-47.

- (1990b): Functional categories and verb movement: The acquisition of German syntax reconsidered. In: Rothweiler, M. (ed.): Spracherwerb und Grammatik. Linguistische Berichte, Sonderheft 3, 190-224.

- (1994): Constraining the child's grammar: Local well-formedness in the development of verb movement in German and French. In: B. Lust, M. Suner \& J. Whitman (eds.): Syntactic theory and first language acquisition: cross-linguistic perspectives, 215-247. Hillsdale, New Jersey: Erlbaum.

Russkaja grammatika-80: Švedova, N. Ju. (ed.):, 1980. Moskva: Nauka, AN SSSR. 